\title{
Metodologias ativas de ensino e aprendizagem: Sala de aula invertida, instrução por colegas e júri simulado no ensino de Matemática
}

\author{
Active Learning Methodologies: Flipped Classroom, peer instruction and the simulated jury in \\ teaching Mathematics
}

Metodologías de aprendizaje activo: Aula invertida, instrucción por colegas y jurado simulado en la enseñanza de las Matemáticas

Recebido: 31/03/2021 | Revisado: 10/04/2021 | Aceito: 13/04/2021 | Publicado: 26/04/2021

Valdineia Rodrigues Lima
ORCID: https://orcid.org/0000-0002-8605-1348
Universidade Federal do Sul e Sudeste do Pará, Brasil
E-mail: valdineia@ unifesspa.edu.br
Edilene França Pereira Sousa
ORCID: https://orcid.org/0000-0002-4450-8397
Universidade Federal do Sul e Sudeste do Pará, Brasil
E-mail: edilene@ unifesspa.edu.br
Camila Maria Sitko
ORCID: https://orcid.org/0000-0003-4620-1388
Universidade Federal do Paraná, Brasil
Universidade Federal do Sul e Sudeste do Pará, Brasil
Centro de Investigação, Desenvolvimento e Inovação do IESF, Portugal
E-mail: camilasitko@ yahoo.com.br

\section{Resumo}

A busca por métodos alternativos de ensino e aprendizagem em Matemática, que substituam as aulas tradicionalmente expositivas e conteudistas, tem sido um desafio para o professor, atualmente. Com o intuito de oferecer alternativas nesse sentido, este estudo apresenta metodologias ativas de ensino e aprendizagem que são adequadas ao Ensino de Matemática na Educação Básica. A fỉm de contribuir no âmbito da atuação docente, foi realizada uma revisão na literatura, na busca da caracterização e da definição de propostas pedagógicas de metodologias ativas para o Ensino de Matemática. Dessa forma, neste trabalho, são destacadas as metodologias Sala de Aula Invertida, a Instrução por Colegas e o Júri Simulado. São apresentados uma breve descrição de cada metodologia, os procedimentos para sua utilização, bem como sua relação com o Ensino de Matemática. O trabalho mostra a relevância, assim como incentiva o uso de metodologias ativas de ensino e aprendizagem no Ensino de Matemática.

Palavras-chave: Metodologias ativas; Ensino de matemática; Sala de aula invertida; Instrução por colegas; Júri simulado.

\begin{abstract}
The search for alternative teaching and learning methods in Mathematics, which replace the traditionally expository and content classes, has been a challenge for the teacher, currently. In order to offer alternatives in this sense, this study presents active teaching and learning methodologies that are suitable for the Teaching of Mathematics in Basic Education. In order to contribute to the scope of teaching, a review of the literature was carried out, seeking to characterize and define pedagogical proposals for active methodologies for the Teaching of Mathematics. Thus, in this paper, the Inverted Classroom, the Peer Instruction and the Simulated Jury methodologies are highlighted. A brief description of each methodology, the procedures for its use, as well as its relationship with the Teaching of Mathematics are presented. The work shows the relevance, as well as encourages the use of active teaching and learning methodologies in the Teaching of Mathematics.
\end{abstract}

Keywords: Active methodologies; Mathematics teaching; Flipped classroom; Peer instruction. Simulated jury.

\section{Resumen}

La búsqueda de métodos alternativos de enseñanza y aprendizaje en Matemáticas, que reemplacen a las clases tradicionalmente expositivas y de contenido, ha sido un desafío para el docente, en la actualidad. Con el fin de ofrecer alternativas en este sentido, este estudio presenta metodologías activas de enseñanza y aprendizaje adecuadas para la Enseñanza de las Matemáticas en Educación Básica. Con el fin de contribuir al ámbito de la docencia, se realizó una revisión de la literatura, buscando caracterizar y definir propuestas pedagógicas de metodologías activas para la Enseñanza de las Matemáticas. Así, en este trabajo, se destacan las metodologías Aula Invertida, la Instrucción por 
Colegas y el Jurado Simulado. Se presenta una breve descripción de cada metodología, los procedimientos para su uso, así como su relación con la Enseñanza de las Matemáticas. El trabajo muestra la relevancia, además de incentivar el uso de metodologías activas de enseñanza y aprendizaje en la Enseñanza de las Matemáticas.

Palabras clave: Metodologías activas; Enseñanza de las matemáticas; Aula invertida; Instrucción por colegas; Jurado simulado.

\section{Introdução}

O êxito da Educação Básica depende de fatores metodológicos, pedagógicos, científicos, sociais e estratégicos, que proporcionem a aprendizagem do aluno, e quando se consegue substituir a forma tradicional de ensino por métodos que possibilitem uma inversão do aluno receptor para protagonista/ativo no processo de aprendizagem, um espaço maior para troca de conhecimento surge, podendo impactar, por exemplo, no aprendizado matemático. Nesse sentido, as metodologias ativas de ensino e aprendizagem propõe auxiliar em tal processo de protagonismo estudantil.

As metodologias ativas de ensino e aprendizagem são aquelas nas quais o aluno torna-se protagonista do processo, rompendo com uma tradição de aulas expositivas e alunos passivos (Gomes et al., 2020). Além disso, estas têm a função de analisar, conhecer, pesquisar e apresentar aos participantes do processo educacional soluções para determinados problemas.

Essas metodologias vêm sendo alvo de pesquisas que visam a participação ativa dos alunos no processo de aprendizagem (Plantin, 2005; Araujo \& Mazur, 2013; Bergmann \& Sams, 2016; Rodrigues, 2020; Gomes et al, 2020) e, mais especificamente, no Ensino de Matemática (Alcântara et al, 2015; Paiva, 2016; Moura, 2017; Pavanelo \& Lima, 2017; Freire, 2019; Rachelli \& Bisognin, 2020), onde é mostrada a necessidade de novas formas de abordagem pelo professor em sala de aula, nas quais o aluno seja responsável pela construção de seu conhecimento, proporcionando assim, condições para uma aprendizagem mais significativa e atrativa para o Ensino de Matemática.

Nas ciências exatas, sobretudo no campo da Matemática, um dos principais obstáculos enfrentados no processo de ensino e aprendizagem é a resistência prévia dos alunos com relação à disciplina. Nesse sentido, acreditamos que para que haja uma aprendizagem mais efetiva no Ensino de Matemática, uma mudança no âmbito da prática docente se faz necessária. Segundo Alcântara et al. (2015), o professor precisa tornar as aulas mais dinâmicas e adotar diferentes estratégias de ensino que auxiliem o aluno na compreensão dos conteúdos. Assim, as metodologias ativas de ensino e aprendizagem voltadas para a Matemática podem contribuir com a prática pedagógica docente, oferecendo técnicas em que o aluno seja o principal ator no processo de sua própria aprendizagem.

Na busca por metodologias ativas de ensino e aprendizagem que facilitem e diversifiquem a disciplina de Matemática, e que corroborem para desmistificação das dificuldades apresentadas na disciplina (antes mesmo de o aluno ter contato com esta), são apresentadas neste trabalho a Sala de Aula Invertida, a Instrução por Colegas e o Júri Simulado, como potenciais auxiliadoras no Ensino de Matemática.

Assim, o texto traz uma contextualização teórica das metodologias ativas de ensino e aprendizagem, seguido de uma discussão e detalhamento dos procedimentos de uso das metodologias citadas. Na sequência, também é abordada a relação e a inserção dessas metodologias no Ensino de Matemática, seguido das considerações finais sobre o tema.

\section{As Metodologias Ativas de Ensino e Aprendizagem}

$\mathrm{Na}$ sociedade contemporânea, existe a necessidade de se refletir sobre metodologias que proporcionem ações pedagógicas que promovam a participação ativa dos alunos no processo de aprendizagem, e assim, possibilitem a interação com os colegas e com o objeto de estudo.

O uso de métodos ativos pode ser capaz de proporcionar a assimilação dos conteúdos na sala de aula, incentiva os alunos a serem independentes, críticos e participativos do processo construtivo de aprendizagem (Gomes et al, 2020). A 
construção do conhecimento matemático ocorre gradativamente, através do contato do aluno com as teorias e com as atividades propostas, solucionando as problemáticas no ambiente de aprendizagem, de modo a desenvolver a capacidade de tomada de decisões e de resolução de problemas (Paiva et al., 2016).

Segundo Moran (2015, p. 18), as metodologias ativas "são pontos de partida para avançar para processos mais avançados de reflexão, de integração cognitiva, de generalização, de reelaboração de novas práticas", e sua utilização no espaço escolar representa uma nova forma de aplicação do conteúdo, de modo a integrar o aluno no processo educacional. Porém, há que se ressaltar que na disciplina de Matemática, a metodologia deve observar o grau de dificuldade do aluno, a explicação clara da teoria, a forma de resolução através das fórmulas Matemáticas, o que torna o processo de aprendizagem mais complexo.

A resistência à Matemática demonstrada pelos alunos, de maneira geral, pode ser resultado de um complexo social, que surge no ambiente social e familiar, refletindo dentro do espaço escolar. Entretanto, em muitas instituições brasileiras, "persiste o modelo tradicional de ensino, em que o professor apresenta os conteúdos e os alunos ouvem, anotam explicações para, somente depois disso, estudar, fazer exercícios e resolver possíveis situações-problema” (Pavanelo \& Lima, 2017, p. 740).

Segundo Vieira, Melo e Bernardo (2016), no Brasil, ainda não se tornou rotina o desenvolvimento de atividades baseadas em argumentação nas salas de aula, evidenciando uma carência na adoção de métodos ativos, que podem ser aplicados tanto no processo de aprendizagem presencial, quanto no ensino à distância. Tais métodos poderiam promover a melhora na qualidade do ensino, redução das dificuldades, e ainda, um aumento na participação ativa dos alunos. Devido a essa necessidade de mudança de abordagem pedagógica, várias pesquisas estão sendo desenvolvidas, a fim de se investigar como as metodologias ativas de ensino e aprendizagem podem ser inseridas na sala de aula.

A aprendizagem ativa se apresenta, segundo Paiva (2016), como um conjunto de práticas pedagógicas que tem como centro o aluno, que passa a aprender por meio da interação pelos pares, estimulando assim o pensamento crítico. A experiência desses alunos deve ser valorizada com a adoção de problemas que façam parte de suas realidades, e que sejam instigados pelo professor "a pensar, refletir, formar e expressar a sua própria opinião, sem precisar abandonar os conhecimentos particulares de cada disciplina" (Paiva, 2016, p. 16).

Conforme demonstrou Glasser (2001) por meio da pirâmide de aprendizado (Figura 1), a aprendizagem ocorre 95\% ao ensinar os outros, $80 \%$ ao fazer, expressar, comunicar, praticar e $70 \%$ ao discutir o tema. 
Figura 1: Pirâmide de aprendizado de William Glasser.

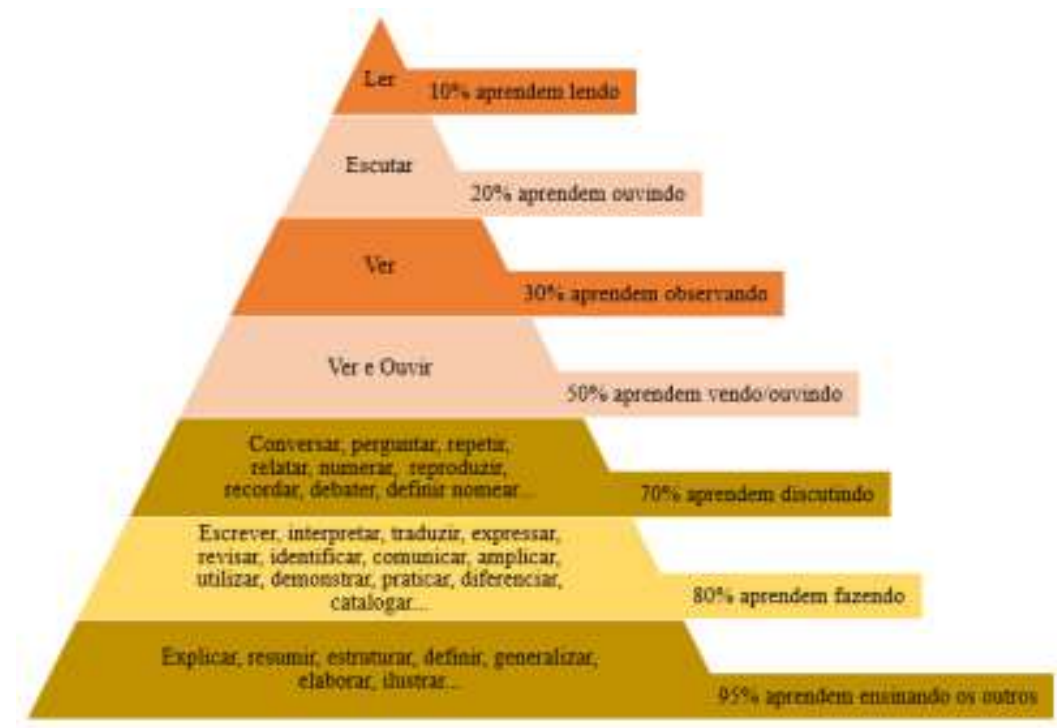

Fonte: Adaptado de Santiago (2018), p.27.

Na pirâmide de aprendizado, é possível observar diferentes padrões de aprendizagem. O nível de aprendizagem passiva varia entre $10 \%$ e 50\%, e os alunos participam lendo, ouvindo, observando, vendo e ouvindo ao mesmo tempo, típico de aulas tradicionais e meramente expositivas. Ou seja, apenas 10\% a 50\% dos alunos aprendem com as ações determinadas pela tabela. Entretanto, à medida que o nível de aprendizagem aumenta, evidencia-se uma aprendizagem mais ativa, em que os alunos participam discutindo, fazendo e ensinando seus colegas. Pode-se observar na pirâmide, que cerca de $70 \%$ a $95 \%$ da turma aprende com as ações como as elencadas. Assim, metodologias que ofereçam a possibilidade de alunos mais atuantes, trazem maiores probabilidades de aprendizagem.

Nesse sentido, são aqui apresentadas e detalhadas algumas metodologias ativas de ensino e aprendizagem que visam otimizar a aprendizagem em Matemática na Educação Básica, levando em consideração a participação ativa do aluno, que o estimulem a conversar, perguntar, discutir, fazer, ensinar aos colegas, entre outros. Tais metodologias são a Sala de Aula Invertida, a Instrução por Colegas e o Júri Simulado.

\section{Abordagem Metodológica}

Esta pesquisa é caracterizada como de abordagem qualitativa, na forma de revisão de literatura. Conforme discorre Godoy (1995, p.21), esse tipo de abordagem "enquanto exercício de pesquisa, não se apresenta como uma proposta rigidamente estruturada, ela permite que a imaginação e a criatividade levem os investigadores a propor trabalhos que explorem novos enfoques".

Visando um aprofundamento com a temática proposta, foi realizada uma revisão de literatura, na busca da caracterização e da definição de propostas pedagógicas de metodologias ativas para o Ensino de Matemática, pois, segundo Moreira (2004, p.24) esse tipo de revisão "pode ser organizada para estabelecer nexos no conhecimento existente", à medida que demanda por leituras críticas dos textos selecionados, o que exige, segundo o autor, uma expertise e conhecimento com a temática, para que haja o crescimento da área de estudo.

Dessa forma, ao selecionar os textos que fundamentaram esta pesquisa, primeiramente buscamos por produções sobre as metodologias ativas que fossem adequadas ao Ensino de Matemática, o que levou à escolha e delimitação da Sala de Aula Invertida, Instrução por Colegas e Júri Simulado. Em seguida, foram buscadas pesquisas desenvolvidas pelos criadores (ou sistematizadores) de tais metodologias, tomando como base os autores Bergmann e Sams (2016), Mazur (2015a), e Alcântara 
et al (2015), respectivamente. Por fim, foi realizado um levantamento da literatura voltado para essas três metodologias, em busca de trabalhos que versaram sobre práticas e aprofundamentos teóricos, ampliando assim, conforme destaca Moreira (2004), o conhecimento sobre o assunto proposto neste trabalho.

\section{Metodologias Ativas de Ensino e Aprendizagem no Ensino de Matemática: Sala de Aula Invertida, Instrução por Colegas e Júri Simulado}

Neste tópico, serão abordadas três metodologias ativas de ensino e aprendizagem, a saber, Sala de Aula Invertida, Instrução por Colegas e Júri Simulado, e suas relações com o Ensino de Matemática, bem como serão apresentados os procedimentos e os conceitos-chave que guiam cada uma.

\subsection{Sala de Aula Invertida}

Muitas mudanças ocorreram e ainda estão ocorrendo no Ensino de Matemática, mas professores ainda são vistos como transmissores de conhecimento. Atualmente, um dos maiores desafios para o professor de Matemática é conseguir trabalhar com seus alunos, de forma eficiente e prazerosa, o conjunto de informações, fórmulas e conceitos necessários para a aprendizagem matemática, devido a ter que competir, em grande desigualdade, com a internet, videogames, computadores, tablets e outros dispositivos tecnológicos, por exemplo.

Nesse sentido, em busca de uma metodologia acessível (do ponto de vista cognitivo e de familiaridade) ao aluno, e que acompanhe o ritmo das tecnologias atuais, de forma que este deixe de ser mero receptor, para ser o "protagonista e aprenda de forma mais autônoma, com o apoio de tecnologias" (Pavanelo \& Lima, 2017, p.740), tornando o aprendizado mais participativo, é que a metodologia da Sala de Aula Invertida se adequou ao propósito da pesquisa, por se aproximar da realidade dos alunos que estão sempre conectados com o mundo virtual.

Tal metodologia é capaz de permitir o atendimento personalizado a cada aluno. Sendo responsável por uma inversão do modelo tradicional de ensino, no qual o professor é o transmissor de informações e o aluno é o receptor, a Sala de Aula Invertida visa colocar o professor como condutor do ensino, a fim de proporcionar ao aluno um aprendizado mais amplo e completo.

Para defini-la, Bergmann e Sams (2016) tratam basicamente de uma inversão do processo tradicional, ou seja, o que comumente é feito em sala de aula (o estudo do conteúdo conceitual), passa a ser realizado na casa do aluno, e o que ele costumava fazer em casa, que são os estudos reflexivos sobre o assunto e onde aparecem as dúvidas, passa a ser feito em sala de aula.

Não existe um método específico para se replicar, ou uma lista de verificação da Sala de Aula Invertida (ou mesmo de outras metodologias ativas) que possa levar a resultados garantidos de aprendizagem. A inversão de sala de aula está relacionada a uma certa mentalidade, a de deslocar a atenção do professor para o aluno e para o seu aprendizado. Cada professor que optar pela reversão terá um método diferente (Bergmann \& Sams, 2016), embora alguns aspectos-chave da metodologia devam aparecer em todas, como o estudo e a avaliação diagnóstica anteriormente à aula, a discussão em sala, e o feedback relativo às questões feitas em casa.

Essa inversão tem a intenção de fazer com que os alunos assumam papeis ativos e, sendo assim, torna-los responsáveis por seus próprios processos de aprendizagem. Além disso, tal metodologia pode auxiliar os alunos tanto devido à flexibilidade de horário, pois podem acessar atividades e vídeos no ambiente on-line quando for conveniente, quanto devido à personalização do ensino que pode ser oferecida pelo professor, ao ser capaz de identificar, previamente à aula, quais são as dificuldades dos seus alunos.

As dificuldades mais específicas podem ser melhor solucionadas com o uso dessa metodologia do que com o método 
tradicional, pois neste último, as atividades são realizadas em casa (e sem monitoramento pelo professor), onde o suporte pedagógico para resolução de problemas muitas vezes é falho, devido a uma série de motivos.

Neste sentido, inverter os papeis pode ser importante, de modo que aluno passa a ter um suporte pedagógico melhor nesse processo, à medida em que o professor dedica uma parcela maior das aulas para resolução de dúvidas coletiva ou individualmente, sobretudo na Matemática, que é uma disciplina dita complexa por grande parte dos alunos da Educação Básica.

Diante desse cenário, pesquisadores vem desenvolvendo trabalhos abordando a Sala de Aula Invertida no Ensino de Matemática (Bravim, 2017; Muraro, 2019; Sanches, 2019; Sanches, Batista \& Marcelino, 2019), mostrando que essa metodologia pode ser utilizada na Educação Básica, desde a séries iniciais do Ensino Fundamental, até o Ensino Médio.

Muraro (2019), por exemplo, analisou a utilização dessa metodologia nas aulas de Matemática em uma turma do $5^{\circ}$ ano do Ensino Fundamental, a partir do uso de uma sequência de atividades referente ao conteúdo de frações, em que os alunos tinham como objetivo identificar e apresentar frações, e identificar frações equivalentes. Para tanto, o vídeo foi um dos caminhos adotados para inverter o tempo da sala de aula.

Os vídeos eram posteriormente contextualizados pelos alunos em sala de aula, que relatavam suas experiências com frações, e, em duplas, realizavam operações envolvendo diferentes situações, relacionando as frações e o cotidiano, notas musicais, jogos e receitas culinárias. Em seguida, os alunos respondiam a questões pertinentes ao acesso ao conteúdo, para que assim, o professor conhecesse suas dinâmicas diante da proposta da Sala de Aula Invertida.

Ainda segundo Muraro (2019), as pesquisas envolvendo essa metodologia no ambiente escolar ainda são poucas, diante dos ganhos pedagógicos: os alunos se tornaram mais participativos ao interagirem com os colegas e a professora. A pesquisa constatou a eficácia da metodologia e ressaltou que pode ser trabalhada no Ensino Fundamental, inclusive nos anos iniciais.

A metodologia também pode ser utilizada no Ensino Médio. Sanches (2019) investigou a contribuição de uma proposta pedagógica ancorada nessa metodologia para o Ensino de Matemática Financeira Básica. Antes de adentrar tal conteúdo, o professor precisou apresentar alguns conceitos e termos relativos ao mundo financeiro para seus alunos, de forma que compreendessem, por exemplo, o que é Educação Financeira, Cartão de Crédito e Inflação.

Uma oficina de Controle de Gastos foi elaborada visando estimular uma gestão eficiente das finanças pessoais. Os temas abordados foram Juros Simples e Compostos, Porcentagem e Investimentos.

Segundo Sanches (2019), os materiais produzidos em sala de aula devem possibilitar que o aluno analise as similaridades e diferenças entre os conceitos abordados, à medida que, nesse momento são retomados os conteúdos estudados on-line para aprofundamento e esclarecimento das dúvidas. Assim, o app Matemática Financeira foi introduzido para verificar se os cálculos realizados pelos alunos sobre Juros Simples e Compostos estavam corretos. A pesquisa constatou que a Sala de Aula Invertida pode ser implementada no Ensino Médio e apresentou indícios da sua contribuição para uma aprendizagem significativa dos conceitos matemáticos estudados.

Bergmann e Sams (2016) apontam algumas vantagens do uso da metodologia:

- O aluno passa a ter um papel ativo, desenvolvendo um maior senso de responsabilidade sobre seu próprio processo de aprendizagem;

- Ajuda os alunos mais ocupados, proporcionando a flexibilidade de tempo, pois podem acessar as atividades e vídeos disponibilizados no ambiente on-line, em um horário que melhor lhes convenha;

- Auxilia os alunos que enfrentam dificuldades no aprendizado, permitindo que o professor tenha mais tempo na sala de aula, podendo este se dedicar mais a sanar as dúvidas dos alunos;

- Possibilita ao aluno rever o conteúdo quantas vezes julgar necessário, pausando e revendo os vídeos; 
- Intensifica a relação professor-aluno e aluno-aluno, pois o professor passa a conhecer melhor os seus alunos, e, através das atividades colaborativas em grupo, os alunos interagem entre si.

A inserção das tecnologias digitais no ensino provoca mudanças importantes no processo de ensino e aprendizagem, sendo responsável por trazer novos desafios e possibilidades que transformam as escolas em espaços dinâmicos de aprendizagem, o que torna os alunos mais motivados para aprender. Para Rodrigues (2020) a Sala de Aula Invertida, parte do ensino híbrido, que faz uma combinação entre o aprendizado on-line com off-line, e precisa de três condições para ser utilizada: momento virtual, momento presencial, e uso de tecnologias digitais que integrem presencial/virtual.

Ao utilizar tal metodologia, o professor precisa pensar uma situação didática em que os alunos possam pesquisar na internet sobre os objetos de estudo. Em seguida, pode ser elaborado, por exemplo, um produto, fruto da pesquisa, e ocorrer a apresentação deste, que pode ser um vídeo, podcast, entre outros, no momento da aula. Nessa etapa, o professor deve estimular a discussão e o debate, de forma a resolver os problemas e dúvidas, de maneira a atender as três etapas da Sala de Aula Invertida: contato com o conteúdo antes da aula, discussão e debate no decorrer da aula, e a consolidação da aprendizagem depois da aula (Rodrigues, 2020). Dessa forma, para a utilização dessa metodologia ativa, o professor deverá:

- Utilizar uma sequência didática que seja apropriada à proposta da metodologia;

- Selecionar o ambiente virtual de aprendizagem que seja mais adequado à proposta da Sala de Aula Invertida, para aplicar os elementos de colaboração, comunicação e cooperação;

- Gravar vídeos curtos ou fazer uso de vídeos prontos, desde que estejam de acordo com o conteúdo a ser trabalhado, para que os alunos possam assistir como conteúdo prévio, podendo rever quantas vezes julgarem necessário;

- Aplicar questionários para avaliar a aprendizagem dos alunos e desenvolver atividades e relatórios, que auxiliarão nesse processo;

- Analisar qual a contribuição dessa metodologia para os alunos, de forma que possam ser desenvolvidas novas pesquisas sobre o uso da Sala de Aula Invertida no Ensino de Matemática.

Para atingir tais objetivos, o Ambiente Virtual de Aprendizagem precisa ser preparado com todos os elementos necessários para a aplicação da metodologia, a saber: inserção das ferramentas colaborativas, como as de comunicação (fórum de discussões para os grupos), de cooperação (Wiki, para a construção do resumo teórico), e de coordenação (agenda virtual, painel de avisos, painel de desempenho), para que sejam armazenados os vídeos, atividades, fórum de dúvidas, e outros que se julgarem necessários.

Dessa maneira, a proposta da Sala de Aula Invertida auxilia o professor a instigar seus alunos a participarem de forma mais ativa, despertando assim o interesse pela Matemática, tendo em vista que lhes possibilitará o desenvolvimento de alguns aspectos, como:

- Formação pessoal: Desenvolver habilidade investigativa em meio a um ambiente virtual de aprendizagem;

- Compreensão do objeto de estudo: Interagir com as ferramentas colaborativas, como a comunicação, cooperação e coordenação;

- Ensino do objeto de estudo: Aprender o conteúdo matemático de forma ativa;

- Busca de informação, comunicação e expressão: Pesquisar em ambientes virtuais e discutir os resultados com os colegas;

- Conhecimento prévio: Relacionar o conteúdo matemático com outras unidades temáticas e associar ao seu cotidiano.

Assim, o papel do professor na proposta de Sala de Aula Invertida é de "orientador, apoiador dessa resolução, auxiliando nas dúvidas do grupo em relação aos conceitos teóricos estudados em casa e na interpretação dos problemas propostos" (Pavanelo \& Lima, 2017, p. 746), possibilitando que o aluno seja o protagonista e que possa aprender Matemática 
de forma mais autônoma, com o apoio das tecnologias digitais.

\subsection{Instrução por Colegas (Peer Instruction)}

Outra metodologia ativa de ensino e aprendizagem é a Instrução por Colegas, também conhecida em inglês como Peer Instruction (Araujo \& Mazur, 2013) ou Instrução por Pares, criada pelo professor e físico da Universidade de Harvard, Eric Mazur, na década de 1990 (Mazur, 2015a). É uma metodologia difundida em diversos países e em contextos diferentes (Rachelli \& Bisognin, 2020), entretanto pouco difundida no Brasil, na área da Educação Matemática.

Essa metodologia visa a participação ativa do aluno no processo de ensino, em atividades que possibilitem-lhe aplicar os conceitos estudados em sala de aula, através da resolução de problemas propostos pelo professor, discussão e convencimento dos resultados aos colegas de classe. Esse método busca promover a aprendizagem do conteúdo da pesquisa por meio da interação entre os alunos (Araujo \& Mazur, 2013).

Nessa perspectiva, atenção que antes era voltada para o professor, na Instrução por Colegas, desvia-se para os alunos, que passam a buscar informações para explicar situações e problemas por meio da pesquisa, para que possam ter uma opinião formada sobre o assunto, e assim, possam discutir e argumentar com os colegas sobre sua posição. De maneira geral, segundo Moura (2017), essa discussão e concordância sobre determinada resposta entre os pares, auxilia de alguma forma na consolidação da aprendizagem, eliminando (ou, ao menos diminuindo) assim possíveis dúvidas que os alunos possam apresentar. Nessa metodologia, ocorre a substituição da aula expositiva tradicional, para que haja mais tempo de interação entre os alunos, de modo que estes sejam ativos dentro do processo de ensino e aprendizagem.

A metodologia é capaz de possibilitar a aprendizagem através de debates entre a turma, fazendo com que a relação professor-aluno passe a ser aluno-aluno e professor, em que o professor deixa de ser o transmissor de conteúdo para tornar-se um treinador, que guia seus alunos. Dessa forma, o ponto central dessa ferramenta não é o instrutor (professor), mas o aluno.

Essa metodologia se apresenta como uma das alternativas para auxiliar os alunos a compreenderem conceitos matemáticos, embora tenha sido desenvolvida pelo professor Eric Mazur, inicialmente para auxiliar no ensino de Física para estudantes de medicina.

Segundo Mazur (2015b), os alunos de medicina tinham aversão à Física antes mesmo de suas aulas começarem. Mesmo assim, conseguiam tirar notas boas nos testes, o que fez Mazur acreditar que era o melhor professor do mundo. No entanto, este acabou percebendo que o êxito de seus alunos era uma ilusão, após ler e replicar uma pesquisa que mostrava, por meio de questões de múltipla escolha e problemas cotidianos, que os alunos aprendiam muito pouco, ou nada, em cursos introdutórios de Física.

Indignado com os resultados apresentados na pesquisa, Mazur (2015b) decidiu aplicar o teste em seus alunos, os quais não alcançaram os resultados esperados. Assim, ele percebeu que estes conseguiam resolver um problema do livro, mas não um problema simples baseado em uma situação real. Isso ocorria devido à Física que estava sendo apresentada a eles, nas aulas expositivas, era como uma receita que podiam memorizar.

Sem saber como solucionar o problema de seus alunos, a solução veio acidentalmente em uma revisão antes do exame final: por mais que tentasse explicar de várias formas um determinado conceito, os alunos não compreendiam, então Mazur acabou sugerindo que os alunos explicassem uns aos outros, numa dinâmica de "quem aprendeu ensina para quem não aprendeu". Surpreendentemente, o que ele não havia conseguido explicar, foi assimilado de forma espontânea quando os colegas ensinavam entre si.

Mazur (2015b) explica que esse fato devido ao aluno que aprendeu o conteúdo recentemente e explicou ao colega, conhece suas dificuldades, enquanto para o professor que sabe esse conteúdo há muito tempo, o aprendizado é óbvio e simples, pois uma vez que se aprende algo, acaba-se esquecendo dos obstáculos que precisaram ser vencidos para que a aprendizagem 
ocorresse.

Após essa descoberta, Mazur (2015b) mudou completamente a forma de lecionar e abandonou as aulas expositivas. Ao invés disso, passou seu livro e anotações para que os alunos lessem em casa, e, na sala de aula, este começou a ensinar por meio de questionamentos. Após explicar por alguns minutos, fazia uma pergunta, os alunos respondiam, em seguida solicitava que encontrassem alguém com uma resposta diferente e que o convencesse. Embora a sala ficasse um caos, pois os alunos tinham que conversar e argumentar, era possível ver o momento em que eles entendiam o conceito/conteúdo em questão. Consequentemente, mais alunos apresentavam respostas corretas quando era retomada a discussão com o grande grupo. A esta atividade, chamou de Instrução por Colegas (Mazur, 2015a).

Para Mazur (2015a), não é possível aprender ouvindo, mas fazendo. Dessa forma, a Instrução por Colegas traz o fazer para sala de aula: os alunos fazem um estudo prévio do material disponibilizado pelo professor antes da aula, sendo desafiados por questões conceituais em sala de aula, o que proporciona a interação entre os estudantes e auxilia no processo de aprendizagem dos conceitos fundamentais da Matemática (ou o objeto de estudos em questão). Embora essa metodologia proporcione um papel ativo no processo de aprendizagem, segundo Rachelli e Bisognin (2020), no Brasil, ainda são poucos os estudos realizados na área da Educação Matemática.

Dentre tais estudos, Paiva (2016) apresenta propostas de uso dessa metodologia no Ensino de Matemática. Freire (2005) também faz uma combinação da Instrução por Colegas e da Sala de Aula Invertida nas aulas de Matemática no Ensino Médio. Entre os conteúdos abordados estão Matrizes, Equação Linear e Solução de uma Equação Linear, Sistemas de equações lineares e soluções de sistemas.

Em algumas aulas dessa proposta, uma planilha do excel do próprio computador do professor foi disponibilizada aos alunos, deixando-o no centro da sala, para que, conforme os alunos concluíssem a questão, pudessem utilizá-lo. A combinação dos dois métodos possibilitou um diferencial nas aulas de Matemática em que foram aplicadas.

Moura (2017) desenvolveu sua pesquisa com alunos do $5^{\circ}$ ano do Ensino Fundamental, utilizando como matriz de referência os descritores da Prova Brasil e o eixo Números e Operações. Cada aluno tinha uma ficha de controle em que anotava as respostas, e havia também uma ficha de controle geral, contemplando todos os resultados da classe. Um ponto positivo apresentado na pesquisa, é que a Instrução por Colegas é capaz de atingir todos os alunos, porque a aula apenas prossegue quando o teste é respondido por todos os alunos.

Para desenvolver essa metodologia, Rodrigues (2020) estabelece alguns procedimentos:

- O professor passa um problema e estabelece um tempo para que os alunos respondam;

- Caso o índice de acertos seja superior a 70\%, é realizada uma explanação geral para sintetizar aprendizagem tema, seguindo para o problema seguinte;

- Se o índice de acertos for inferior a 70\%, o professor deve dividir a turma em grupos pequenos, para que os alunos possam debater qual seria a resposta certa;

- Após os debates, a questão é retomada ao grande grupo, e uma nova votação de resposta correta é feita;

- Caso o índice de erros fique abaixo de 30\%, realiza-se a sistematização da aprendizagem e segue para o próximo problema;

- Se o índice de erros permanecerem acima de 30\%, o professor precisa aprofundar a explanação do conteúdo, buscar alternativas de abordagem, e explicar aos alunos o motivo da questão estar errada.

Diante do exposto, cabe a reflexão que metodologias tradicionais, focadas no professor, com aulas expositivas, embora sejam dominantes na cultura educacional, não atendem às demandas do século XXI, sendo necessário ressignificar o papel do professor e do aluno nesse processo. Nessa percepção, a Instrução por Colegas apresenta vantagens que podem impactar positivamente na aprendizagem, pois o seu uso "no Ensino de Matemática resulta em aprendizagem significativa" 
(Moura, 2017, p. 68).

\subsection{Júri Simulado}

A Educação Básica depende de diversos aspectos para melhorar a qualidade educacional, tendo em vista que, o contexto social, o familiar e o econômico podem influir de maneira direta na qualidade do aprendizado do aluno. Assim, o professor precisa buscar métodos que auxiliem nesse processo; é nessa perspectiva que o Júri Simulado entra em ação.

Tal metodologia pode ser importante no Ensino de Matemática, pois contribui para formar cidadãos a partir de atividades que envolvem o lúdico, os conteúdos matemáticos lecionados, seu posicionamento crítico e argumentação, e que consegue abranger uma quantidade maior de alunos, levando em consideração a superlotação nas turmas de Matemática na Educação Básica.

Para Alcântara et al. (2015, p. 19), o Júri Simulado "é uma estratégia de ensino que permite a discussão dos vários pontos de um mesmo tema, divide opiniões, auxilia no processo de construção e desconstrução de conceitos”, o que desenvolve no aluno, sobretudo, aspectos como senso crítico, participação nas atividades e reflexão. É baseado na simulação de um júri, no qual o grupo analisa e avalia os fatos reais de um problema de forma objetiva, através dos argumentos de defes a e acusação. A implementação dessa metodologia é complexa porque requer do professor uma organização e visão que vão além dos métodos expositivos (Moran, 2015).

As modificações e adaptações no processo do júri fazem parte do processo educativo e devem ser gerenciadas pelo professor, principal responsável nesse espaço, de modo que este conduza uma relação sólida com o ensino matemático, durante o júri. Desse modo, o aluno não realiza apenas cálculos na aula de Matemática, mas participa ativamente do seu processo de ensino, à medida que lida com vários desafios, discute e interage com os colegas, favorecendo o aprendizado matemático.

As pesquisas envolvendo o Júri Simulado estão mais voltadas para a Educação Superior, como a de Vieira (2016), que se voltou para a formação dos professores de Física, e Mendes (2017), que trabalhou com o curso de Pedagogia. No entanto, embora escasso de pesquisas voltadas para o Ensino de Matemática, apresenta-se neste trabalho como um potencial recurso para auxiliar no aprendizado dos alunos da Educação Básica.

Alcântara et al. (2015) analisaram a utilização do Júri Simulado e Phillips 66 ${ }^{1}$, em uma turma de Matemática de um curso técnico do Ensino Médio. Entre os conteúdos trabalhados estão a Progressão Aritmética (PA) e a Progressão Geométrica (PG). A utilização dessas metodologias possibilitou aulas mais dinâmicas e interativas, tornando a aula mais prazerosa, instigando a curiosidade e a vontade de aprender no aluno.

Não foram localizadas pesquisas voltadas para o Ensino Fundamental, o que mostra que essa metodologia ainda carece de pesquisas destinadas para o Ensino de Matemática, principalmente voltados à Educação Básica.

Stumpf e Oliveira (2016) ressalta que o uso de situações cotidianas proporciona uma melhor compreensão teórica por parte do aluno, que passa a associar, analisar, criar hipóteses e fazer conclusões. Desse modo, o Júri Simulado parte de problemas reais, de forma que o aluno, através de argumentos de defesa e acusação, possa realizar análises e avaliações de fatos com objetividade e competência. Tal metodologia possibilita a realização de várias operações do pensamento, visto que o aluno terá que aprofundar seus conhecimentos em determinados assuntos, para que possa estabelecer relações entre os temas e assim, conseguir argumentar de forma favorável ou contrária ao problema proposto.

Para desenvolver a atividade do júri os alunos devem assumir, de forma engajada, um determinado papel, como juiz, oponente e defensor. O professor pode ser o mediador ou assumir uma função, de forma que ao final da divisão, haverá o

\footnotetext{
1 Trata-se de uma atividade grupal em que são realizadas análises e discussões acerca de temas e problemas do contexto do aluno. Desenvolve operações do pensamento como análise, interpretação, crítica, hipóteses, suposições e organização de dados. Para maiores detalhes sobre Phillips 66, ver Alcantara et al (2015).
} 
grupo do contra, o grupo a favor, e juízes.

A dinâmica envolve, a partir de um problema, apresentação de argumentos de acusação e defesa, e pode ser desenvolvida pelo professor, conforme Anastasiou e Alves (2006) e Alcântara et al. (2015) mostram, seguindo as seguintes etapas:

- Simular um júri em que os alunos, em grupos, irão analisar e avaliar um problema a partir de um fato real, através de argumentos de defesa e acusação;

- Organizar qual aluno assumirá o papel de juiz e de escrivão;

- Dividir os demais alunos em quatro grupos: promotoria; defesa (um a quatro alunos cada grupo); conselho de sentença (sete alunos) e plenário (demais alunos);

- Orientar e definir os dias e o tempo, em média 15 min, para que promotoria e defesa apresentem seus argumentos;

- Avaliar a apresentação, considerando a clareza, a lógica das ideias, a profundidade dos conhecimentos e a fundamentação dos argumentos.

Quanto aos papeis desenvolvidos nessa dinâmica, Anastasiou e Alves (2006) indicam que o juiz será responsável por formular os requisitos ao conselho de sentença e manter a ordem das atividades; os relatórios de trabalho serão de responsabilidade do escrivão; ao conselho de sentença incube a apresentação da decisão final, após ouvir os argumentos de defesa e acusação; o plenário também tem um papel de observação e deve apresentar, ao final do caso, uma apreciação quanto ao desempenho e desenvoltura da promotoria e da defesa (Plantin, 2005).

Dessa forma, pode-se perceber que o Júri Simulado possibilita que os alunos desenvolvam "a reflexão filosófica e científica a respeito de temas que demandam uma análise teórica maior" (Mendes, 2017, p. 4943). O método desenvolve no aluno a capacidade argumentativa, a tomada de decisões, a defesa das ideias, julgamentos, além de promover o senso crítico.

Assim, o Júri Simulado se apresenta como potencial recurso alternativo para abordar questões matemáticas complexas, para lidar com alternativas e contra alternativas em relação a determinado assunto, o que possibilita ao aluno raciocinar, comunicar e argumentar, contribuindo assim para o desenvolvimento de várias competências matemáticas, como

utilizar estratégias, conceitos e procedimentos matemáticos, em seus campos - Aritméticos, Álgebra, Grandezas e Medidas, Geometria, Probabilidade e Estatística -, para interpretar, construir modelos e resolver problemas em diversos contextos, analisando a plausibilidade dos resultados e a adequação das soluções propostas, de modo a construir argumentação consistente (Brasil, 2018, p. 523).

São muitas as possibilidades de aprendizagem por meio do Júri Simulado na Matemática, pois esta proporciona ao aluno a "interpretação, crítica, imaginação, observação, comparação, elaboração e confirmação de hipóteses" (Alcântara et al., 2015, p. 27). Além disso, por ser uma atividade em grupo, promove a interação e a capacidade do aluno de se relacionar com os colegas, por meio de aulas dinâmicas e prazerosas que estimulem a curiosidade e promovam a vontade de aprender, contribuindo para o aprendizado matemático.

\section{Considerações Finais}

Neste trabalho, foram apresentadas três metodologias ativas de ensino e aprendizagem que auxiliam no Ensino de Matemática na Educação Básica, visando contribuir no âmbito da prática docente para tornar as aulas de Matemática mais atrativas e motivadoras, com a participação ativa dos alunos.

As metodologias ativas selecionadas foram a Sala de Aula Invertida, a Instrução por Colegas e o Júri Simulado, tendo em vista que contribuem para interações sociais destinadas à construção do conhecimento, estimulando o desenvolvimento de habilidades metacognitivas, à medida que o aluno passa a criar hábitos de estudos e ter um maior controle 
sobre o que aprende, sem desconsiderar seu conhecimento prévio.

Entretanto, para que ocorra uma transformação na sala de aula, tais métodos devem ser implementados com o comprometimento e dedicação do professor, pois demandam tempo, conhecimento, adequação ao currículo, produção de materiais, criação de estratégias, entre outros.

O professor precisa ter em mente que almejar resultados diferentes demandam mudança de postura em sala de aula. Nas metodologias ativas, o docente passa a atuar como mediador do processo de ensino e aprendizagem, com vista a superar o modelo tradicional das aulas de Matemática, trazendo uma participação mais ativa do aluno, por meio de discussões e desafios que possibilitem soluções compartilhadas.

Nesse contexto, a Sala de Aula Invertida possibilita uma verdadeira inversão do modelo tradicional de ensino, da versão verticalizada do docente como transmissor de informações, para condutor do ensino, e do aluno passivo para protagonista, o que possibilita um aprendizado matemático mais amplo e autônomo, com o apoio das tecnologias digitais.

Uma metodologia que pode ser combinada com esta primeira é a Instrução por Colegas, que possibilita a aprendizagem através de debates, na qual o professor deixa de ser o transmissor para se tornar um treinador, que guia seus alunos. Assim, a relação professor-aluno passa a ser aluno-aluno e professor, o que proporciona a interação entre os alunos e auxilia no processo de aprendizagem de conceitos fundamentais da Matemática.

Outra metodologia apresentada foi o Júri Simulado, que parte de problemas reais que possibilitem aos alunos, por meio de argumentos de defesa e acusação, realizarem análises e avaliações. Como possibilita a realização de várias operações do pensamento, é um potencial recurso alternativo para abordar questões Matemáticas complexas, pois lida com alternativas e contra alternativas em relação a determinado assunto, e faz com que o aluno possa raciocinar, comunicar e argumentar, contribuindo assim, para o desenvolvimento de várias competências matemáticas.

Diante do exposto, é possível inferir a relevância da utilização de metodologias ativas de aprendizagem no Ensino de Matemática, visto que possibilitam um aprendizado mais prazeroso e significativo para o aluno.

No entanto, foi evidenciada uma carência na utilização dessas metodologias na Educação Básica, no que tange a Matemática. Por isso, foram apresentados exemplos de utilização dessas metodologias e procedimentos para sua utilização nas aulas de Matemática da Educação Básica, de forma contribuir com a prática pedagógica do docente. Dessa forma, espera-se que esta pesquisa motive professores de Matemática a utilizarem as metodologias ativas de ensino e aprendizagem apresentadas, bem como trabalhos futuros que abordem outros métodos de aprendizagens ativas e estudos que avaliem o potencial impacto na aprendizagem dos alunos com a utilização das metodologias ativas no Ensino de Matemática.

\section{Referências}

Alcântara, L. A. G., Quartieri, M. T., Marchi, M. I., \& Dullius, M. M. (2015). As estratégias de ensino júri simulado e phillips 66 como facilitadores do ensino e da aprendizagem na disciplina de matemática. Revista Eletrônica Sala de Aula em Foco. 4 (1), 17-28.

Anastasiou, L. G. C., \& Alves, L. P. (2006). Estratégias de ensinagem. In: anastasiou, L. G. C, Alves, Leonir Pessate (org.). Processos de ensinagem na universidade: pressupostos para as estratégias de trabalho em aula (6a ed). Univille.

Araujo, I. S., \& Mazur, E (2013). E. Instrução pelos colegas e ensino sob medida: uma proposta para o engajamento dos alunos no processo de en sinoaprendizagem de Física. Caderno Brasileiro de Ensino de Física, 30 (2), 362-384.

Bergmann, J., \& Sams, A. (2016). Sala de aula invertida: Uma metodologia ativa de aprendizagem. (A. C. C. Serra Trad). LTC.

Brasil. Ministério da Educação. MEC. (2018). Base Nacional Comum Curricular. Educação é a Base. Ensino Médio. Brasília, DF.

Bravim, J. D. (2017). Sala de aula invertida: proposta de intervenção nas aulas de matemática do Ensino Médio. (Dissertação de Mestrado). Instituto Federal do Espirito Santo, Vitória, ES, 2017.

Godoy, A. S. Pesquisa qualitativa: tipos fundamentais. Revista de Administração de Empresas, 35(3), 20-29.

Glasser, W. (2011). Teoria da Escolha: uma nova psicologia de liberdade pessoal. Mercuryo. 
Research, Society and Development, v. 10, n. 5, e2810514507, 2021

(CC BY 4.0) | ISSN 2525-3409 | DOI: http://dx.doi.org/10.33448/rsd-v10i5.14507

Gomes, H. S., Sitko, C. M., Oliveira Sá, S., \& Costa-Lobo, C. Metodologias ativas na educação presentes na prática pedagógica em uma escola estadual de ensino médio na modalidade de ensino integral na cidade de Marabá-PA. FINOM. 27, 2020.

Mazur, E. (2015a). Peer Instruction - A Revolução da Aprendizagem Ativa. Editora Penso.

Mazur, E. (2015b). Instrução pelos pares na aprendizagem ativa (legendado). https://www.youtube.com/watch?v=iCDXyIrYNS8.

Mendes, A. A. (2017). Aceitação do Júri Simulado como Estratégia Didática no Curso de Pedagogia. Anais eletrônicos do Educere - Congresso Nacional de Educação. Curitiba, PR.

Moran, J. (2015). Mudando a educação com metodologias ativas. In: C. A Sousa, O. E. T. Morales (Org), Convergências Midiáticas, Educação e Cidadania: aproximações jovens. (pp. 15-33).

Moreira, W. (2004). Revisão de literatura e desenvolvimento científico: conceitos e estratégias para confecção. Janus, 1(1), 21-30.

Moura, B. L. (2017). Aplicação do Peer Instruction no ensino de matemática para alunos do quinto ano do ensino fundamental. (Dissertação de Mestrado) Escola de Engenharia de Lorena, Universidade de São Paulo, Lorena-SP.

Muraro, M. I. (2019). Sala de aula invertida nas aulas de matemática no ensino fundamental - anos iniciais. (Dissertação de Mestrado. Setor de Educação, Universidade Federal do Paraná, Curitiba, PR.

Paiva, T. Y. (2016). Aprendizagem ativa e colaborativa: uma proposta de uso de metodologias ativas no ensino da matemática. (Dissertação de Mestrado). Universidade de Brasília, Brasília, DF.

Paiva, M. R. F., Parente, J. R. F., Brandão, I. R., \& Queiroz, A. H. B. (2016). Metodologias ativas de ensino-aprendizagem: revisão integrativa. Revista de políticas públicas - SANARE, 15 (2), 145-153.

Pavanelo E., \& Lima, R. (2017). Sala de aula invertida: a análise de uma experiência na disciplina de Cálculo I. Bolema, 31 (58), $739-759$.

Plantin, C. (2005). L'argumentation. Presses Universitaires de France.

Rachelli, J., \& Bisognin, V. (2020). Peer Instruction: uma experiência no ensino de cálculo com base em metodologias ativas de aprendizagem. Revista Eletrônica de Educação Matemática - REVEMAT, 15 (1), 01-21.

Rodrigues, E. (2020). Guia de metodologias ativas: com Google for Education. Hub Educat UFPE.

Sanches, R. M. L. (2019). Metodologia sala de aula invertida nas aulas de matemática financeira básica: uma proposta para o ensino médio. (Dissertação de Mestrado). Instituto Federal de Educação, Ciência e Tecnologia Fluminense, Campos dos Goytacazes, RJ.

Sanches, R. M. L, Batista, S. C. F., \& Marcelino, V. S. (2019). Sala de aula invertida em aulas de matemática financeira no ensino médio: reflexões sobre atividades e recursos didáticos digitais. Novas Tecnologias na Educação, 17 (1), 476-485.

Santiago, S. A. (2018). Ensino da meiose: o que o aluno dos cursos de ciências agrárias, ciências biológicas e ciências da saúde aprendem e o que deveriam aprender. (Dissertação de Mestrado). Instituto de Biologia, Universidade Estadual de Campinas, Campinas, SP.

Stumpf, A., \& Oliveira, L. D. (2016). Júri simulado: o uso da argumentação na discussão de questões sociocientíficas envolvendo radioatividade. Experiência em Ensino de Ciências, 11 (2), 176-189.

Vieira, R. D., Melo, V. F., \& Bernardo, J. R. R. (2016). O júri simulado como recurso didático para promover argumentações na formação de professores de física: o problema do "gato". Ensaio, 16 (3), 203-226. 